\title{
Imaginando otros Futuros : niños y escuelas en contextos de pobreza en la Argentina de los noventa
}

Patricia Raquel Redondo

Universidad de Buenos Aires

\section{Resumen}

Este artículo tiene como objeto abordar la relación entre la educación y la pobreza en la Argentina de los noventa, a partir de una mirada construida desde el campo de la investigación que reconoce los cambios cualitativos que se han producido en el país al configurarse nuevas fronteras de exclusión. Comprender cómo estos procesos de profunda pauperización atraviesan la educación implicó dirigir nuestra mirada a los sujetos que transitan y habitan las escuelas en estos contextos de extrema pobreza y, en particular, los niños. Para ello, se analizan fragmentos de sus historias de vida recogidos a partir de un estudio etnográfico realizado en una escuela en una "villa de emergencia" (llamada "favela" en Brasil y/o las "poblaciones" en Chile).

Esta investigación nos permite indagar, conocer, comprender cómo las estrategias de supervivencia que llevan adelante cotidianamente los niños investigados se entrelazan con los significados otorgados a la escuela, tensionando en el presente la posibilidad de otros futuros. Los testimonios y su análisis nos habilitan a pensar a los niños/adolescentes y jóvenes nombrados como pobres, marginales y excluidos desde otras posiciones como sujetos con capacidad de "alterar lo dado" y situarse como constructores de otras realidades.

Abonar esta perspectiva permite discutir que las nuevas fronteras de exclusión no clausuran las posibilidades de educar. Por el contrario, reconocer el lugar asignado a la escuela por parte de los niños investigados, en el orden de imaginar y proyectar otros futuros posibles, permite dar cuenta de la constitución de diferentes subjetividades e identidades no necesariamente inscriptas en relaciones subalternas establecidas hegemónicamente.

\section{Palavras-chave}

Correspondência para:

Zelada 4574 depto.4 Exclusión - Niñez - Escuela - Subjetividades. 


\section{Imagining other futures : children and schools in contexts of poverty in Argentina of the nineties}

Patricia Raquel Redondo

Universidad de Buenos Aires

Correspondence:

Zelada 4574 depto.4

Cap.Federal, $A R$

Cod. Postal 1407

Email: boido@rcc.com.ar

* and in English, "slum" or

"shanty town"

\section{Abstract}

The aim of this paper is to discuss the relationship between education and poverty in the Argentina of the nineties from the standpoint of a research framework that recognizes the qualitative changes that occurred in the country when new boundaries of exclusion were established. Understanding how these processes of deep impoverishment pervade education has required focusing on the subjects that pass through and inhabit the school in these contexts of deep poverty, and in particular on the children. For that an ethnographic study was carried out at a school located in a shantytown (called "villa de emergencia" in Argentina) during which fragments of the subjects histories of life were collected and analyzed.

The study allows us to question, to learn and to understand how the survival strategies adopted routinely by these children interact with meanings they assign to the school, contrasting in the present the possibility of other futures. The testimonies and their analysis enable us to think about these children/adolescents and youngsters - labeled as poor, outcasts and excluded - from a different perspective, seeing them as subjects with the ability to "change the picture" and position themselves as makers of other realities.

Adopting this viewpoint it is possible to argue that the new boundaries of exclusion have not trapped the possibilities to educate. On the contrary, recognizing the role assigned to the school by the children studied here have allowed us to explicate the constitution of different subjectivities and identities not necessarily embedded in submissive relationships established hegemonically.

\section{Key words}

Exclusion - Childhood - School - Subjectivity. 
En América Latina la niñez ha sido y continúa siendo, cada vez con mayor patetismo, el rostro más agudo en el que parecen sintetizarse los conflictos sociales, culturales y políticos de sociedades cada vez más empobrecidas. A la manera de un verdadero síntoma social la situación infantil revela su padecer, heridas en muchos casos incurables, herencias de padres y abuelos que alguna vez también, allá lejos, fueron azotados por pestes, hambre o violencias varias en lo que parece ser recurrentes complicidades generacionales (Carli, 1991, p.13).

Instalados en la fragilidad social, en la peligrosidad de los márgenes, en la trampa integradora de la asistencia, en la vulnerabilidad como frontera o pasaje hacia la exclusión, se constituyen sujetos sujetados a la privación así como también sujetos deseantes de otros futuros.

El objeto de este trabajo es reconstruir, a modo de síntesis, fragmentos de las historias de vida de niños que viven en una "villa de emergencia" nos Aires $^{2}$ y que, desde un estudio etnográfico sobre escuelas en contextos de pobreza, nos permitió recuperar los significados que le otorgan a la escuela y su lugar como sujetos constructores de realidades.

Este trabajo sintetiza, por una parte, reflexiones provenientes de la experiencia laboral vinculada al sistema escolar en zonas signadas por la pobreza extrema y por otra, los avances de un trabajo de investigación que aún continúa en el marco del Proyecto APPEAL (Alternativas Pedagógicas y Prospectiva Educativa en América Latina) $)^{3}$ en escuelas en dichos contextos en el ámbito del Conurbano Bonaerense. ${ }^{4}$

Los procesos actuales de pauperización en la Argentina de los noventa, no son un efecto residual que representa una disfuncionalidad del sistema, sino por el contrario, son parte estructurante del modelo social y económico que se ha consolidado en esta última década. El mismo pone en cuestión la gobernalidad y legi- timidad del sistema democrático y del sistema de educación pública.

La pobreza aumenta en magnitud extendiéndose e incluyendo sectores que antes no se los consideraba pasibles de ser afectados por estos procesos al mismo tiempo que además, modifica su espesor. Esto da lugar a la construcción de nuevos sentidos y significados en torno a qué es ser pobre en los noventa.

Por otro lado, se produce una concentración exacerbada de la riqueza configurando un nuevo mapa social en la Argentina, afianzando un modelo que configura nuevas fronteras de exclusión. Desde nuestra perspectiva, esta problemática excede a los sujetos de la pobreza, por lo cual considera-

1. En la Argentina se denominan "villas de emergencia" a los barrios pobres que rodean a las grandes urbes; esta denominación es sinónimo de "favela" en Brasil o "población" en Chile. En nuestro país, en las décadas de los años 40 y 50 estos asentamientos urbanos se ubicaron en la periferia, hoy están localizados también en el centro de las ciudades. En los años 60, en las villas de emergencia se organizó un movimiento social que adquirió relevancia política en esa década en nuestro país. En la actualidad, los que habitan en estos barrios son estigmatizados socialmente y se los culpabiliza de la falta de "seguridad" en las ciudades.

2. La Argentina tiene una organización Republicana Federal con un Gobierno Central y 24 jurisdicciones autónomas: 23 Provincias y la Ciudad Autónoma de Buenos Aires que es la Capital Federal de la República. La Provincia más importante es la Provincia de Buenos Aires. En el sistema educativo de esta juridicción se concentra el $32 \%$ de los docentes (208.025 según el Censo Nacional de Docentes y Establecimientos de 1994) y el $35,5 \%$ de los alumnos (3.129.312 según la misma fuente) del total del país.

3. El Proyecto APPEAL es un Programa de investigación dirigido por la Dra. Adriana Puiggrós, con sede en la Facultad de Filosofía Y Letras en la UBA (Universidad de Buenos Aires) y, en la UNAM (Universidad Nacional Autónoma de México) desde el año 1991 y que aún continúa. Este trabajo de investigación se realizó en el marco de una producción colectiva sobre la Prospectiva educativa en nuestro país desarrollado durante los años 1996/98 dirigido por la Prof. Inés Dussel de la UBA.

4. El Conurbano Bonaerense es el territorio de mayor concentración demográfica, económica y política de la Argentina. En su conjunto es el conglomerado urbano más densamente poblado. Según los datos del Censo de 1991 la población total de los 19 partidos que lo componen es de 7.924.324 personas, revistiendo la misma característica demográficas y laborales netamente urbanas. La mayoría de los establecimientos educativos del país están ubicados en este territorio que rodea la Capital Federal y que en otros momentos se configuró como el principal cordón industrial de la Argentina. Hoy, es donde se condensan las cifras más altas de desocupación y precarización laboral. 
mos que "la mirada debería dirigirse más que a los sectores excluidos y pobres, hacia los procesos de exclusión, pauperización y subalteralización" (Danani, 1995).

Las escuelas argentinas que históricamente fueron construidas con un fuerte mandato igualador, hoy se ven desbordadas por las políticas que desigualan y diferencian. En contextos de pobreza extrema, ubicadas en los límites, en los bordes, entre la inclusión y la exclusión, se constituyen como "la última frontera de lo público” (Redondo, 1999).

\section{La escuela de Villa Palito 5}

Villa Palito representa no sólo la delimitación de un territorio y un espacio reconocido como "la villa" sino que también se constituye como un espacio simbólico, en una trama compleja en la que se teje una red de significaciones que incluyen diferentes imágenes, deseos y subjetividades de quienes alli viven o trabajan.

Relevar qué sucedía con los sueños y realidades tanto de los niños como de los adultos de la escuela de Villa Palito se constituyó en uno de los aportes más significativos del trabajo de campo de esta investigación. Nos propusimos investigar y conocer las historias de vida de, entre otros, Juan, Ricardo, Cecilia, alumnos de la escuela. Entrar en diálogo con sus cotidianeidades nos permitió indagar sobre el entrelazamiento de sus representaciones imaginarias sobre el futuro con los significados que le otorgan a la escuela en el presente. Para ello, no sólo se realizaron entrevistas individuales y grupales dentro de la escuela sino que, con el objeto de conocer su vida cotidiana nos aproximamos a sus núcleos familiares y a otros espacios en la villa por fuera de la misma.

Apropiarnos de la realidad de las escuelas en los márgenes desde otras perspectivas teóricas que incluyan la complejidad de su problemática implica "la necesidad de articular las distintas posibilidades que pueden conformar la urdimbre de la realidad" (Zemelman, 1992, p. 81).

\section{Juan y la escuela: fragmentos de una historia de vida}

Juan es miembro de una familia numerosa de once hermanos, el último recién nacido. Durante el trabajo de campo la historia de Juan despertó nuestra "sensibilidad etnográfica” (Fonseca, 1998) ya cursa su sexto grado por la mañana pero también asiste a la escuela a la tarde y a la noche. Nos interrogamos sobre los motivos de su presencia tantas horas en la escuela y partiendo del supuesto que su entorno familiar era el que lo impulsaba a realizar este esfuerzo decidimos indagar en su núcleo familiar. Sin embargo, su madre nos expresa durante la entrevista realizada en su vivienda en la villa, que no conoce demasiado lo que hace Juan en la escuela. Sí sabe que asiste muchas horas, más de las obligatoriamente tendría que ir. Ella asocia esa actitud a que Juan esté imitando la historia de su propia infancia que transcurrió internada en un instituto de menores, pero no lo sabe.

Juan, al igual que muchos chicos de su edad que viven en la villa, parece estar a cargo de sí mismo hace mucho tiempo, cartonea y moja los cartones para que pesen más a la hora de entregarlos y recibir una miserable paga. Sabe, y así nos lo manifiesta, que las opciones no son tantas ni mejores que aquella. Puede incluirse en la mendicidad, la prostitución o la venta de droga y pasarla en los pasillos de la villa pero de todos modos como él lo expresa: "se cobra poco, estás muy expuesto a la yuta ${ }^{6}$ y después es muy difícil zafar”.

$\mathrm{Al}$ igual que sus compañeros de la villa y de la escuela entrevistados, con los cuales comparte su tiempo, tiene total claridad sobre su realidad. La describe sin omitir ningún detalle, reconociendo su condición de "pibe villero"” que lo marca en cualquier ámbito y en

\footnotetext{
5. "Villa Palito" es la denominación de la villa de emergencia en la cual se desarrolló esta investigación.

6. Yuta: con este término se denomina popularmente a la policía.

7. Niño habitante de barrios marginados.
} 
cualquier espacio que transite. Los procesos de diferenciación que se producen respecto a esta "marca villera" se profundizan cuando se cruzan con la problemática vinculada al género, situación que se vuelve explícita en los relatos de niñas y adolescentes, alumnas de sexto y séptimo grado de la escuela investigada.

Este "ser villero" como marca opera como diferencia hacia afuera y también dentro de la villa. Al hablar de diferencia, abonamos la perspectiva de McLaren (1994), que la considera

\begin{abstract}
no como zonas nítidamente marcadas de experiencia autointeligible no como una unidad de identidad dentro de un pluralismo cultural. Más bien, la diferencia debe considerarse como producto de una política de significación, es decir, de prácticas significativas que reflejan y constituyen las relaciones políticas y económicas prevalecientes (p.29).
\end{abstract}

En el caso de los maestros, entrar en la escuela de la villa se constituye en un verdadero obstáculo por no pertenecer a la misma. Para un maestro que enseña en la escuela y que decidió vivir en el barrio nos comenta: "el problema es que no son maestras villeras, no conocen los códigos". Pertenecer, ser de la villa, se configura como un polo de identificación que funciona como un punto nodal importante en la constitución de identidades.

La investigación nos permite afirmar que esta identificación como "pibes villeros" que los diferencia, los define y fija a la territorialidad de la pobreza no implica la homogeneidad al interior de la misma. Por el contrario, el conocimiento de sus historias de vida nos habilitan a pensar que si bien sus propias realidades, especialmente a partir de los diez años ${ }^{8}$, los confrontan y obligan a todos por igual a la necesidad de encontrar modos de sobrevivir o de ayudar a la economía familiar; estas estrategias se entraman y significan de modo diferente respecto del lugar que ocupa la escuela en sus historias de vida presentes y futuras.
Los recorridos escolares diferentes que realizan les permiten ocupar distintas posiciones como sujetos a las que se configuran como predeterminadas por su condición de pobreza. Hacia allí dirigimos la mirada.

Juan no es de los que abandonó la escuela tempranamente, ocupando las rutas, limpiando vidrios o vendiendo chipá ${ }^{9}$ a pesar de que en quinto grado sólo asistía una vez cada tanto a clases y era considerado un desertor. Así nos lo relata la directora de la escuela:

Con Juan trabajamos con algunos maestros desde gabinete pero no obteníamos resultados. Los toma una maestra que hizo un laburo bárbaro con los pibes tanto que ese grado que era un grado con ausentismo creciente e incluso expulsor empezaron a no faltar nunca y Juan termina pidiendo a sus maestros el doble turno. No tiene donde estar, obvio que no figura ni en planilla nada, pero viene todos los días todo el día. Juan dibuja muy bien, él ni se había dado cuenta que dibuja como los dioses, entonces está haciendo todas las ilustraciones para un friso del Rey León. Es una cosa, no se quiere ir de acá y viene también a la noche. Esto significa que cuando la escuela ofrece lo que tiene que ofrecer los chicos no se quieren ir de acá adentro.

Al momento de la investigación, Juan le dedica casi todos sus tiempos a la escuela aunque reconoce que le cuesta mucho aprender, entonces redobla sus esfuerzos y asiste no sólo en el turno mañana sino que también se queda a la tarde y cursa en el Centro de Adultos de la noche. Tiene una ventaja, sus maestros que lo conocen, valoran sus esfuerzos y le dan

8. El trabajo de campo realizado y la experiencia de trabajo en barrios en contextos de pobreza nos permite hipotetizar que se establece un límite etáreo respecto a los cuidados y responsabilidades de los adultos hacia los niños e incluso desde el Estado. Pasados los diez, once años ya no son privilegiados por los diferentes programas de intervención estatal y además comienzan a asumir responsabilidades domésticas 0 de aporte económico al grupo familiar.

9. Chipá: una clase de pan que producen y consumen los sectores populares del interior del país. 
permiso para estar más horas en la escuela de lo que corresponde. Él dice con orgullo:

Yo vengo a la mañana y a la tarde, hago las guías que me da el maestro, ya estoy terminando la diez (la última que entregó el maestro a todo el grado, y sonríe).

Diariamente, entra y sale de la escuela, tiene libertad para hacerlo, come, circula por los pasillos de la villa y vuelve. Cumplimenta las guías que le organiza su maestro del turno mañana con otra maestra en el turno de la tarde. Nos habla de su futuro y es allí, en esa dimensión temporal, que para él la escuela cobra sentido. Las imágenes de otros futuros posibles ligados a su escolaridad ubican el recorrido por la escuela como parte de una estrategia con proyección en el tiempo.

Desde nuestra perspectiva, en oposición a los supuestos que sostienen que quiénes viven en contextos de pobreza extrema sólo atienden su presente inmediato, en el caso de los alumnos de la escuela de la villa investigados es en el orden de otra temporalidad, futura, no tangible, imaginaria que se significan sus esfuerzos en el presente en su vínculo con la escuela.

Lo que satura su vida cotidiana, la miseria, el maltrato, la falta de espacio, la necesidad de supervivir es lo que Juan y sus compañeros ya conocen. Son los circuitos donde se entra y no se puede salir fácil. Son los que denominamos, desde nuestra investigación los circuitos del terror (Redondo, 1999).

Acá la mendicidad es histórica. En la escuela hay muchos chicos que trabajan, se los considera, se los respeta, aunque no se incorpora que este chico trabaja a la actividad de la escuela.

Equipo de orientación escolar.

Algunos lo hacen en un peladero de huesos cercano pero para poder trabajar allí se ven obligados a mentir respecto a su asistencia a la escuela porque sino no los toman.
Los que los explotan tienen temor que la escuela intervenga porque trabajan en condiciones infrahumanas, ilegales. Ya lo hemos hecho y luego los echan. Los chicos nos piden que no hagamos nada. La situación te genera mucha impotencia.

Bibliotecaria de la escuela.

Juan le otorga a la escuela un lugar relevante en su propia historia que se entreteje y tensiona entre el agravamiento de sus condiciones de vida y la construcción de otras posibilidades presentes y futuras depositadas en sus aprendizajes en la escuela y en el vínculo con sus maestros. La investigación nos permite corroborar las perspectivas que se sitúan en "rescatar al sujeto como constructor de realidades" (Zemelman, 1994, p.21) entendiendo el desarrollo social e histórico como "un campo que contiene múltiples opciones de construcción".

\section{Rutas, cárceles y escuela: identidades escindidas.}

Otros, a diferencia de Juan ocupan las rutas y también las cárceles.

\begin{abstract}
Agrupados en el semáforo, esperan que los autos se detengan. Son varios, llevan puesto el buzo del "Verano Feliz" del Plan Pibes. Trabajan a unos cientos de metros de la escuela. Se acercan a los autos y les limpian los vidrios sin esperar el consentimiento.
\end{abstract}

Nota de campo en Ruta 3.

La ruta es uno de los espacios en el cual pasan parte importante del día trabajando. Ya sea como "limpiavidrios", "vendedores de chipá” u otras tareas, siempre en relación de dependencia de adultos que los explotan. No siempre la paga es en dinero, a veces sólo les ofrecen droga a cambio. Varios de ellos van a la escuela e irrumpen en el espacio escolar con los elementos que usan para limpiar autos. 
En las rutas son los "sin nombre", los "sin rostro". Sin embargo, son o fueron alumnos de la escuela de la villa, a la hora del mediodía cruzan la ruta y van a ella. En este cruce, en este pasaje, en este entrar en el espacio escolar no sólo traspasan el umbral de la puerta sino que también se incluyen aunque sea en forma fugaz e intermitente en otro espacio que, a diferencia de la ruta, los reconoce y los nomina como sujetos. Sin desconocer por ello que en determinados momentos también los estigmatiza.

$\mathrm{Al}$ volver a la ruta y abandonar el banco reiteran una vez más su deserción cotidiana del aprendizaje pero de modo recurrente cada día vuelven a la escuela en tanto se constituye como el único espacio que les permite desde la mirada de los otros, adultos constituirse en "pibes" ubicados en un tiempo de infancia.

El análisis de las notas de campo nos permitió reconstruir estas situaciones de entrada y de salida del espacio escolar de estos chicos y cómo esto tensiona de modo particular a la escuela al confrontarse con una situación para la cual no fue pensada y que la atraviesa cotidianamente.

Son pasadas las doce, ya se está terminando de brindar el servicio de comedor que se sirve en las aulas en el turno mañana. En media hora más ingresan los alumnos que comen en la escuela del turno tarde, son casi todos.

Los maestros y auxiliares llevan y traen jarras, fuentones de plástico con pan y ollas. Hay mucho movimiento. La puerta de la escuela permanece abierta. En esos momentos entra un grupo de chicos, los 'limpiavidrios de la ruta', son alumnos de la escuela. Vienen a comer. La cocinera se dispone a darles, otra auxiliar se queja de tener que darles comida si a clase no vienen. Se acerca la asistente social dialoga con ellos, interviene para que coman y les pregunta cómo están, insistiéndoles para que vengan a la escuela a estudiar. Ellos contestan que sí, se rien, prometen que mañana vienen. Bueno, los esperamos.
Comen, circulan por toda la escuela saludan a sus amigos y se van. Un clima particular se produce en la escuela a pesar que es una situación bastante conocida. Cada uno rápidamente sigue con su tarea ya están llegando los del turno tarde, los maestros tratan de comer rápidamente para irse a otro cargo, el personal auxiliar limpia. La puerta sigue abierta.

Nota de campo en la escuela.

Las posiciones de docentes, auxiliares, personal directivo, se dividen y confrontan entre quienes intentan sostener el vínculo con los chicos y, a partir de su presencia cotidiana, insistir para que ocupen sus bancos y quienes postulan la necesidad de expulsarlos y no darles de comer porque en esas condiciones ya no son más alumnos de la escuela. Para el análisis de estas situaciones las categorias de alumno y de desertor no son suficientes en sí mismas para comprender este pasaje.

Creo que hay dificultades, todo te significa un esfuerzo mayor, para el que está aquí, es una realidad hay obstáculos para todo pero hay que insistir.

Asistente Social de la escuela.

Insistir cotidianamente para retener, para que no abandonen la escuela, para que estudien es parte de la tarea de los maestros de la escuela en la villa, compartida también por el personal auxiliar, cooperadores. Lo paradojal, de esta situación es que a los que se llaman indistintamente acentuando su condición marginal, "los limpiavidrios", "los que se drogan", "los que mendigan”, no abandonan definitivamente la escuela. Entran, la rodean, ocupan los techos, se aproximan, la agreden e incluso la violentan pero la requieren y la demandan. Así lo testimonia una nota de campo realizada en el patio de la escuela.

Víctor está arriba en el techo de la escuela. Tira piedras a sus compañeros que están en el 
patio. Hoy, no entró a la escuela pero a media mañana se instaló en sus techos. Dialoga con sus compañeros que están en recreo. Su maestra, lo ve y le pide que baje, él no lo hace pero tampoco se va.

Son niños y adolescentes, expulsados del tiempo de la niñez, de un tiempo de infancia que requeriría ser asegurado y garantizado por los adultos y el Estado. Excluídos, pugnan por ser incluidos, reconocidos y nominados. Desde el margen, violentan las fronteras que los excluyen. De diferentes modos se vinculan y significan la escuela y a sus maestros como un espacio privilegiado socialmente por ellos.

Otro dato significativo, que abona este análisis y posibilita otras lecturas es que no es su situación de extrema pobreza, de necesidad, lo único que determina de modo excluyente, el acercamiento de los chicos a la escuela a la hora del almuerzo, ya que, en la villa el comedor escolar no es el único ámbito en que estos chicos pueden alimentarse porque funciona otro, diariamente en la parroquia.

Es necesario que la escuela comprenda estos procesos desde otros órdenes de interpretación más complejos que permita recuperar las múltiples articulaciones entre educación y pobreza. Es en el terreno de la constitución de los sujetos, en el que se dirime el lugar de las escuelas en contextos de pobreza extrema, en la comprensión de estos procesos y en la potencialidad de la escuela para producir otra inscripción simbólica en tanto espacio social, curvando la vara hacia la inclusión, frente a los procesos que empujan aceleradamente a estos niños y adolescentes a una vertiginosa "desafiliación social" (Castel, 1995).

En el caso de la escuela investigada no es la asistencia como respuesta a las necesidades básicas insatisfechas de sus alumnos que los clasifican como pobres, lo que se pondera. Es su posible intervención en esta "zona de vulnerabilidad" en la reconstitución de este lazo social, en la construcción de un vínculo pedagógico que posibilite la producción de otras identidades y subjetividades.

Los maestros y la escuela interpelan a los niños-adolescentes de la villa como alumnos constituyéndose en un espacio simbólico, en el cual se los reconoce, se los llama por su nombre, se les reclama e insiste que asistan a aprender, a ocupar un lugar, que es el banco del grado. Las estrategias institucionales para retener a estos alumnos que desertaron en algún momento de su trayectoria escolar no siempre logran su cometido. Las más de las veces queda este objetivo limitado a los esfuerzos aislados por parte de los maestros y la escuela desresponsabilizándose el Estado con capacidad de intervención para garantizar la escolaridad de esta franja de la niñez en condiciones de pobreza extrema.

En otros momentos históricos en la Argentina, como en el período 1945-1955 en el cual todos los niños eran considerados sin distinciones como "privilegiados" (Carli, 1994) esta consideración se expresaba directamente en la intervención estatal.

Hoy, en momentos en que se extiende y profundizan los procesos de pauperización en nuestro país afectando principalmente a los niños ${ }^{10}$ la desatención del Estado y la existencia sólo de políticas focalizadas para abordar esta problemática plantea serios problemas para su solución y para la consolidación de la legitimidad de un modelo societal democrático y de una ética que reconozca a todos y a cada uno de estos niños como sujetos de derecho.

Por otro lado, la escuela frente a esta problemática se tensiona, demanda y requiere de la presencia de estos chicos como "alumnos", como sujetos educables, con guardapolvo blanco que deben venir a aprender aquellos aprendizajes prescriptos y necesarios en un espacio socio-histórico pensado y

10. Los últimos datos proporcionados por el Instituto Nacional de Estadísticas y Censo (INDEC) indicam que el $42 \%$ de los niños que habitam en el Conurbano Bonaerense son pobres. 
concebido para ello. Al no lograrlo, y conformarse su realidad cotidiana con niños con hambre, que mendigan o trabajan, sin útiles ni libros, sin guardapolvos, la escuela sujetada y sobredeterminada por el contexto de pobreza parece no poder llevar a cabo su mandato homogeneizador e igualador a riesgo de sólo reproducir y profundizar las diferencias.

Es en la cotidianeidad escolar donde se confrontan y tensionan posiciones de los maestros y las escuelas, frente a las situaciones generadas por la pobreza. En un abanico amplio, se ubican aquellas que intentan llevar a cabo la tarea de enseñar como un acto civilizatorio, incluyendo a estos chicos como alumnos al espacio escolar dejando todos aquellos indicios que den cuenta de su situación de pobreza fuera de la escuela. En el otro extremo se encuentran aquellas escuelas que se posicionan como un espacio incluyente y necesario para los más excluidos para darles herramientas que les posibiliten poder pensarse como sujetos de derecho y salir de su condición de pobreza.

En la escuela tienen que aprender a defender lo que les corresponde, darse formas organizativas para conseguir cosas desde el lugar de marginalidad de dónde viven.

Directora del Conurbano Bonaerense

En la escuela investigada uno de los lugares en que se condensan los sentidos de la inclusión y la exclusión es la puerta. Permanece abierta durante todo el día, a pesar de quienes pugnan dentro y fuera de la misma por cerrarla, éste se convierte diariamente en un espacio de negociación. Desde nuestra perspectiva, el cierre de la puerta de la escuela en horario escolar no es sólo un aspecto normativo de funcionamiento sino que en estos contextos de fuerte exclusión delinea y marca "fronteras educativas".

La directora expresa:

Acá todo el mundo puede entrar. La puerta está siempre abierta.
La puerta abierta en la escuela investigada implicó instituir prácticas democratizadoras que posibilitase la inclusión de todos y de todo aquello que antes, las ventanas tapiadas con maderas, los portones cerrados impedían entrar. También entraron las realidades de sus alumnos.

Pedro estaba preso. Desde chico no tenía mamá, vivía con el padre y los hermanitos. Comienza a robar por necesidad. En el año 81, al llegar a séptimo grado roba y recuerdo que la maestra tuvo que ir a la comisaría a buscarlo para que lo dejen salir el día que tenía que recibir el diploma. Después empieza a tener una caída, va a Olmos y trae todo lo de allá, fue cada vez peor no pudimos hacer más nada a la escuela ya no venía más.

Maestra que trabaja en la villa hace más de quince años

Mendicidad, prostitución, tráfico de droga, trabajo infantil polos de identidades escindidas que se constituyen en los márgenes y que en la escuela se expresan con singular patetismo. Quienes hacen referencia a las escuelas “urbano-marginales” reducen su problemática a la deserción. Sin embargo el pasaje al que hicimos referencia en párrafos anteriores, de alumno regular a desertor, de desertor a alumno implica procesos sumamente complejos que atraviesan la cotidianeidad escolar.

Los alumnos-desertores de la escuela de Villa Palito, sentados en los bancos o habitando los techos buscan sentidos de pertenencia, abandonando la escuela y volviendo a ella en la medida en que ésta genere posibilidades de inclusión y de reconocimiento. Pensarlos fijados a la categoría de alumno o de desertor no permite dar cuenta de los múltiples sentidos con que estos niños-adolescentes significan a la escuela más allá de las particularidades de la misma y como se entraman esos significados con la matriz incluyente o excluyente de la escuela. 
"Para la pedagogía, la infancia es un hecho dado, un supuesto indiscutible a partir del cual es posible construir teórica y prácticamente al alumno" (Carli, 1994, p.63). Sin embargo a la hora de pensar en las realidades de las escuelas en los márgenes las historias de vida de sus alumnos "denuncian los límites y la crisis de la matriz de infancia" (ibid., p.9).

Este trabajo abona la construcción de nuevos conocimientos y saberes para poder comprender y explicar estos procesos en los que se constituyen identidades escindidas o fragmentadas entre la articulación de niñez, educación y pobreza.

\section{La toma de la palabra y la escuela}

La historia de Ricardo también nos habla de la escuela, perdió su hermano mayor en la ruta hace poco tiempo y no encuentra consuelo. Es muy frecuente que mueran chicos atropellados en la ruta que contornea la villa. La muerte atraviesa la cotidianeidad del barrio y ello incluye también a la escuela. La pérdida de estos alumnos se produce en circunstancias casi todas ellas evitables, porque las causas están ligadas directamente a sus agravadas condiciones de vida que se traducen en la agudización de la situación de riesgo en la que viven.

Ricardo le escribe a su mamá para consolarla por la muerte de su hermano, lo hace en la biblioteca de la escuela que le permite "tomar la palabra” y significarla. Nos relata que él viene a la escuela todos los días, no falta porque le gusta y además tiene que comer en la escuela.

Yo como acá, a la noche le hago creer a mi mamá que no tengo hambre y le dejo mi plato de comida a mis hermanitos.

En su relato asume la responsabilidad de ayudar a su mamá, de aliviarla material y afectivamente, en esa dirección la escuela casi sin saberlo, ocupa un lugar preponderante. Le permite la palabra, narrar y narrarse como así también resolver sus necesidades más apremiantes. En las condiciones de vida de su grupo familiar, Ricardo estrecha sus lazos familiares asumiendo responsabilidades respecto a sus hermanos menores. Se incluye en una estrategia familiar que facilite la crianza de los más pequeños, en una práctica singular articulada a su experiencia escolar. Fuera de la escuela ocupa un lugar adulto haciéndose cargo de la situación de su familia para buscar dentro de la escuela una temporalidad negada por sus condiciones de vida. Un tiempo de infancia, en que el eje es aprender e ir a la escuela para ello.

\section{Cecilia es una niña y le gusta leer}

Es temprano para Cecilia, ya que ella viene al turno tarde pero es de mañana y llegó a la escuela a primera hora, está en la biblioteca. Hoy, vino sola habitualmente trae a sus hermanos más pequeños de los que está a cargo. Mira y lee libros de cuentos. En diálogo con ella nos relata:

Somos ocho, a la mayor no la conozco porque vive en la Capital Federal, la otra tiene tres hijos, una sobrina mía murió porque la maltrataban, ahora la extraño. Yo les decía que no le pegasen, le pegaban porque lloraba. Yo vivo con mi papá que arregla teles, mi mamá nos viene a visitar a las cuatro de la mañana, la veo en la parada de colectivo. No sé donde trabaja de cinco a nueve. Sigue hilvanando su relato, siempre con un libro abierto en la mano, al levantar la mirada, afirma "a mí me gusta leer."

La presencia de Cecilia en contraturno es frecuente en la escuela. La mayor parte del tiempo lo pasa en la biblioteca con sus hermanos más pequeños. La Biblioteca ocupa un espacio físico precario, sus dimensiones son reducidas pero cuenta con personal docente a cargo, la bibliotecaria. Ella está atenta a facilitarle a los chicos de la escuela todos los 
espacios y momentos posibles para que lean y escriban. Así como también brindarles los libros para el aula ya que no tienen propios o los de lectura en la biblioteca. Le sorprende la afinidad de los chicos por el lugar ya que vienen y se quedan varias horas.

Ellos piden especialmente libros de cuentos incluso aquellos que se supone que no son para su edad. Los que les atraen más, son los que tienen muchas imágenes, poco texto y en particular, los que relatan historias donde los personajes malos siempre son vencidos por los buenos. Historias de desamparos, pérdidas y obstáculos con personajes maléficos pero con final feliz. Los desenlaces se contrastan notablemente con el afuera.

Les gustan los cuentos con humor no así los de terror. Yo pienso que en la realidad el terror en que viven supera la ficción. Cuentan cosas terribles que pasan en el barrio, que acuchillaron a uno y otras anécdotas. Por eso supongo que buscan los de humor o los clásicos.

Bibliotecaria de la escuela.

Los libros más retirados son: "Hansel y Gretel”, "Los Tres Chanchitos”, "La Bella Durmiente”, "Cenicienta”, "El Príncipe Sapo", "Simbad el marino", "Alicia en el país de las maravillas", "La Bella y la Bestia”, "Caperucita Roja”.

En la villa, fuera de la escuela, sus biografías infantiles se hallan marcadas por historias duras, propias o próximas. El pasaje de la niñez a la pubertad y a la adolescencia es abrupto y precoz. Quedan rápidamente situados como niños-adultos despojados de sus tiempos de infancia. Inscriptos "en un tiempo precario en el que las relaciones de sujeción, sufrimiento, desposesión y desprecio por la dignidad humana y la inviolabilidad de la vida permanecen en el centro de nuestra existencia social" (Mc Laren, 1994, p.17).

Estos relatos de vida de las cuales hemos presentado sólo algunos fragmentos nos permiten pensar que la relación entre narrativa, identidad y ética construye otras posibilidades pedagógicas para las escuelas en contextos de pobreza.

Juan, Ricardo, Cecilia, buscan espacios y éstos son habilitados por la escuela investigada. Espacios desde los cuales se los reconozca desde su infancia y se los trate de ese modo en "un reclamo de individualidad que implica una narrativa que reconoce aspectos temporales y éticos del saber humano" (Mc Laren, 1994, p.38).

Desde la investigación, hemos podido relevar el trabajo obstinado de algunos maestros orientado a que los chicos puedan construir su propia narrativa contrastándolas con otras. La reconstrucción de sus historias propias, de la historia del barrio en que viven, como por ejemplo, Villa Palito o el reconocimiento de otras lenguas como el guaraní en el espacio escolar se orienta a la comprensión de sus realidades y a la construcción de una mirada crítica sobre las mismas.

La posibilidad de tomar la palabra, de narrar nos plantea la necesidad de enfatizar la cualidad dialéctica de esta narración ya que son "narradas al ser vividas y vividas al ser narradas", produciéndose otras articulaciones discursivas que configuran identidades en el vínculo con la escuela. La narración no alcanza pero es necesaria y "no es posible fuera de la trama político-pedagógica del narrador y del narrado. No hay relato sin sujeto" (Puiggrós, 1994, p.34).

Para los docentes reconocer el contexto de la escuela y las condiciones de vida de los niños-adolescentes, alumnos-desertores de la escuela implica poder comprender las relaciones de desigualdad ocultas bajo la enunciación del concepto de diferencia. "Que cuando se lo aplica a los problemas de raza, clase, género, edad, preferencia sexual, o inhabilidad pueden ser absorbidos en lo que yo llamo un puralismo muerto. El pluralismo muerto es lo que mantiene a raya la necesidad de historizar la diferencia, de reconocer la producción 
jerárquica de sistemas de diferencia en los cuales dichas jerarquías favorecen la diferencia...forjada dentro de relaciones asimétricas de poder" (Mc Laren, 1994, p.29).

El trabajo de investigación nos permitió bucear los múltiples sentidos y significados que los niños y adolescentes le otorgan a la escuela de Villa Palito. Se puede afirmar que los mismos configuran una trama discursiva que incluye a los maestros y resignifica la potencialidad y la calidad del vínculo pedagógico. Esta última no se asocia exclusivamente a las características personales de los maestros sino al lugar que en tanto educadores ocupan posicionados pedagógicamente frente a la posibilidad y capacidad de alterar o de incidir de algún modo en "las biografías anticipadas" (Frigerio, 1992, p.31) de sus alumnos.

Ubicados estos últimos en una relación que los interpela como niños, vuelven a un lugar social y a un tiempo de infancia del cual la pobreza los desplazó bruscamente. Adquiere relevancia repensar "el sentido de generatividad, o sea la capacidad de gestar a la generación subsiguiente, de intervenir en sus formas de constitución, de construirla socialmente" (Pichon Riviere y Quiroga, apud Carli, 1994, p.3).

Problematizar la relación de educación y pobreza permitiría construir otros conocimientos y saberes respecto al lugar de la escuela en estos contextos como espacio de construcción de identidades y subjetividades en las que se rearticulen las diferencias y se recuperen estos sentidos antes mencionados.

Desde nuestra perspectiva de análisis los relatos de vida de Juan, Ricardo, Cecilia y otros, nos hablan de un sujeto constituído por diferentes posiciones, para el cual la condición de pobreza no se manifiesta como una postura esencialista que los configura sólo como "niños pobres" como una entidad sustancial previa. Este argumento se orienta a "atacar la clásica noción de sujeto como una entidad sustancial y esencial, dada de antemano" (Zizek, 1993, p.258) recuperando los planteos teóricos de La- clau y Mouffe respecto a la producción de una serie de posiciones particulares de sujeto cuya significación no está dada a priori. "Ellas cambian según el modo en que aquéllas son articuladas en una serie de equivalencias a través del excedente metafórico que define la identidad de cada una de esas posiciones." (apud Zizek, 1993 p.258).

Estos sueños y realidades de estos niños-adultos "no ocultan la dimensión traumática del antagonismo social” (Zizek, 1993, p.259). Sin embargo, nos abren la posibilidad de pensar la condición de un sujeto complejo, estructurante y estructurado, contradictorio, no necesariamente fijado y determinado exclusivamente por su condición de pobreza. Este modelo social y económico que es polarizante nos presenta

dos formas de exclusión: la que tiene que ver con los bienes materiales, concretamente con no tener hambre o frío o enfermedades de la pobreza, o sea no tener sufrimiento físico. Ese es el umbral de humanidad. La otra es social y política: dejamos de pertenecer a la humanidad cuando quedamos afuera de la comunidad (Jelin, 1996, p.18).

Es en esta última forma de exclusión en que la escuela investigada les propicia a los niños la restitución de su lazo social, no por la virtual asistencia o "asistencia inconclusa" (Redondo, 1999) que les brinda el Estado, sino por su inscripción en una comunidad, una historia, una memoria, en el reconocimiento como sujetos de derecho, como "sujetos plenos de participación" (Villareal, 1996, p.172).

Cecilia no encuentra en otro lugar que no sea en la escuela la oportunidad de aprender y en ese aprender a leer y al leerse se proyecta un deseo cultural.

El "a mí me gusta leer" de Cecilia resignifica la posibilidad de la palabra, la posibilidad del deseo. Y, es en la producción de 
ese deseo, que el espacio escolar se configura como el "lenguaje de la posibilidad" (Giroux, 1993).

Junto con Guattari pensamos que "cuando algo se transforma verdaderamente, se trata de deseo, y no de comunicación de saber" (Guattari, 1995). Por lo cual, el lugar de la escuela en estos contextos adquiere relevancia no sólo por los contenidos que puede transmitir sino por la producción y proyección del deseo por conocer, por aprender que inscribe en las historias de vida de sus alumnos.

En las escuelas en los márgenes las categorias de niñez y de infancia se complejizan. Desde aquella concepción de la infancia ahistórica, universal y esencialista a pensar la misma, contextualizada, como una construcción social e histórica de múltiples identidades en las cuales se condensan relaciones de clase y de género, se abre un amplio espectro. En estos fragmentos de las historias de vida investigadas se expresa "la crisis profunda de las categorias con que significamos la infancia, la escolarización y la niñez" (Narodowski, 1994, p.61) agudizándose en el caso de los niños-adolescentes como sujetos de pobreza pero mostrando simultáneamente como se puede actuar e intervenir en las grietas y fisuras de esta crisis provocando la participación activa de cada uno en la hechura de su propia historia.

El análisis realizado de los testimonios recogidos, presentados en este trabajo sintéticamente, nos permiten conocer cómo niños-adolescentes direccionan sus esfuerzos en el presente para alterar lo que se presenta como inevitable definido por sus "biografías anticipadas". Comprender, reconocer y descubrir la existencia de estos procesos permiten elaborar otros cursos de acción. Es en el orden de imaginar y proyectar otros futuros posibles que esta decisión produce la no sutura del discurso hegemónico sobre la niñez y la pobreza en nuestro país, generando rupturas en la cadena discursiva que se establece entre niñez en condiciones de pobreza y marginalidad, peligrosidad social y delincuencia infanto-juvenil con su consecuente penalización.

Las imágenes que los alumnos de la escuela de la villa proyectan hacia el futuro son productivas y creadoras de otras significaciones imaginarias respecto a la escuela, a su realidad y a su presente alterando de algún modo "la fatalidad automática" de las cadenas simbólicas (Colombo, 1993, p.53) hegemónicamente establecidas en relación a la educación y a la pobreza.

\section{Referências Bibliográficas}

CARLI, S. Infancia y sociedad: la mediación de las asociaciones, centros y sociedades populares de educación. In: PUIGGRÓS, A. Sociedad civil y Estado, en los orígenes del sistema educativo argentino: historia de la educación en la Argentina. Buenos Aires: Editorial Galerna, 1991. t.2.

CARLI, S. Historia de la infancia: una mirada a la relación entre cultura, educación, sociedad y política en Argentina. Escuela y Construcción de la Infancia: revista del Instituto de Investigaciones en Ciencias de la Educación, Buenos Aires, v.2, n.4.

CASTEL, R. Las metamorfosis de la cuestión social: una crónica del asalariado. Buenos Aires: Editorial Paidós, 1997.

CASTEL, R. De la exclusión como estado a la vulnerabilidad como proceso. Archipiélago: cuadernos de crítica de la cultura, Barcelona, n.21, 1995.

COLOMBO, E. (comp.) El imaginario social. Montevideo: Altamira Editorial, 1993.

DANANI, C. Los procesos de pauperización en la Argentina. 1995. [mimeografado] 
FONSECA, C. Caminos de adopción. Buenos Aires: Eudeba, 1998.

FRIGERI0, G.; POGGI, M. Las instituciones educativas: cara y ceca, elementos para su comprensión. Buenos Aires: Troquel Educación, 1992.

GIROUX, H. La escuela y la lucha por la ciudadanía: pedagogía crítica de la época moderna. México: Siglo XXI, 1993.

GUATTARI, F. Recrear lo social. Archipiélago: cuadernos de crítica de la cultura, pobreza y peligro, Barcelona, n.21, 1995.

JELIN, E. Una ética para la gente invisible. Clarín, Buenos Aires, 4 feb. 1996.

LACLAU, E. Nuevas reflexiones sobre la revolución de nuestro tiempo. Buenos Aires: Nueva Visión, 1993.

Mc LAREN, P. Pedagogía crítica, resistencia cultural y la producción del deseo. Cuadernos REl, Buenos Aires, 1994.

PUIGGRÓS, A. Sujetos, disciplina y curriculum en los orígenes del sistema educativo argentino. Buenos Aires: Editorial Galerna, 1994.

PUIGGRÓS, A.; GÓMEZ, M. Alternativas pedagógicas: sujetos y prospectiva de la educación latinoamericana. Buenos Aires: Miño y Dávila, 1994.

PUIGGRÓS, A. Volver a educar: el desafío de la enseñanza argentina a finales del siglo XX. Buenos Aires: Editorial Ariel, 1997.

REDONDO, P.; THISTED, S. Las escuelas "en los márgenes": realidades y futuros. In: PUIGGRÓS, A (comp.). En los límites de la educación: niños y jóvenes del fin de siglo. Rosario: Homo Sapiens Ediciones, 1999.

VILLAREAL, J. La exclusión social. Buenos Aires: Grupo Editorial Norma, 1996.

ZEMELMAN, H. Los horizontes de la razón: dialéctica y apropiación del presente. Barcelona/México: Anthropos/El Colegio de México, 1992.

ZEMELMAN, H. Racionalidad y ciencias sociales. In: CÍRCULOS de reflexión latinoamericana en ciencias sociales: cuestiones de teoría y método. Barcelona: Anthropos, 1994. (Suplemento n.45)

ZIZEK, S. Más allá del análisis del discurso. In: LACLAU, Ernesto. Nuevas reflexiones sobre la revolución de nuestro tiempo. Buenos Aires: Nueva Visión, 1993. (Apéndice).

Recebido em 08 out. 1999

Aprovado em $14 \mathrm{dez} .1999$ 